Pacific Journal of Mathematic 


\title{
ISOPERIMETRIC EIGENVALUE PROBLEM OF EVEN ORDER DIFFERENTIAL EQUATIONS
}

\author{
SuI Sun Cheng
}

\begin{abstract}
This paper is concerned with the following eigenvalue problem
\end{abstract}

$$
\left\{\begin{array}{l}
x^{(2 n)}+(-1)^{n+1} \lambda p(t) x=0 \\
x^{(2 k)}(0)=0=x^{(2 k)}(1), \quad k=0,1, \cdots, n-1,
\end{array}\right.
$$

where $p(t)$ is assumed to be positive and continuous in $[0,1]$. For the class of functions $q(t)$ which are equimeasurable to $p(t)$, we shall show that the rearrangement of $p(t)$ in symmetrically increasing order maximizes the least positive eigenvalue of (1), while the rearrangement of $p(t)$ in symmetrically decreasing order minimizes it.

Rearrangements of sets of numbers and functions are defined and investigated in detail in the book by Hardy, Littlewood and Pólya [11, Chapter X] and the book by Pólya and Szegö [18]. Using these notions, classes of nonhomogeneous strings, membranes, rods and plates with equimeasurable densities are considered in $[3,4,5$, 10] and the extremum of the principal frequencies are found for these classes. In particular, the above assertion has been proven by Beesack and Schwarz [5] and Fink [10] for $n=1$. For $n=2$, the proof is given by Banks [3]. Our proof will differ from those given for the special cases in that we will rely on some of the results in the theory of positive operators $[12,13,14,15,16,17]$ and certain rearrangement inequalities $[18,19]$. All the required results will be explicitly stated in the sequel; the explanations of which, however, will be brief.

2. Rearrangement inequalities. Let $h$ be a real function defined on a subset $S$ of $R^{n}$, we shall denote the level set

$$
\{t \in S: h(t) \geqq c\}
$$

by $L(h, c)$. Two real functions $f(t)$ and $g(t)$ defined on $[0,1]$ are called similarly ordered if, for each pair of points $t_{1}, t_{2}$ of $[0,1]$, we have

$$
\left[f\left(t_{1}\right)-f\left(t_{2}\right)\right]\left[g\left(t_{1}\right)-g\left(t_{2}\right)\right] \geqq 0 ;
$$

$f$ and $g$ are called oppositely ordered if $f$ and $-g$ are similarly ordered. If for each $c \in R$, the measure of $L(f, c)$ is equal to that of $L(g, c)$, then we say that $f$ and $g$ are equimeasurable. Let $f, \check{f}$ and $\hat{f}$ be equimeasurable, and in addition let $\check{f}(t)$ and $(2 t-1)^{2}$ be 
similarly ordered, and $\hat{f}(t)$ and $(2 t-1)^{2}$ be oppositely ordered. The uniquely defined and continuous functions $\check{f}(t)$ and $\hat{f}(t)$ are called the rearrangement of $f(t)$ in symmetrically increasing, respectively decreasing order (for detail of these statements and their validity, see [11, Chapter X]).

Lemma 1. ([11, Theorem 378 and 18, p. 153]). Suppose $f, f_{1}, f_{2}$, $g, g_{1}$ and $g_{2}$ are real continuous functions defined on $[0,1], f_{1}$ and $g_{1}$ are similarly ordered, $f_{2}$ and $g_{2}$ are oppositely orcered, $f, f_{1}$ and $f_{2}$ are equimeasurable, and also $g, g_{1}$ and $g_{2}$ are equimeasurable, then

$$
\int_{0}^{1} f_{2} g_{2} \leqq \int_{0}^{1} f g \leqq \int_{0}^{1} f_{1} g_{1}
$$

Call a real function $h$ defined on a convex subset $S$ of $R^{n}$ quasiconcave if each of its level sets $L(h, c)$ is convex [2, p. 145]. The following is a slightly modified version of a result of Vollman [19, Theorem 2.1].

LEMMA 2. Let $K(t, s)$ be a continuous, nonnegative, quasiconcave function defined on $[0,1] \times[0,1]$ which satisfies $K(t, s)=K(1-t$, $1-s)$. Let $p, q$ be nonnegative, continuous functions defined on $[0,1]$ with $\hat{p}, \hat{q}$ their rearrangements in symmetrically decreasing order. Then

$$
\int_{0}^{1} \int_{0}^{1} K(t, s) p(s) q(s) q(t) d s d t \leqq \int_{0}^{1} \int_{0}^{1} K(t, s) \hat{p}(s) \hat{q}(s) \hat{q}(t) d s d t .
$$

We remark that under the same assumptions in Lemma 2, the original version only asserts that

$$
\int_{0}^{1} \int_{0}^{1} K(t, s) p(s) q(t) d s d t \leqq \int_{0}^{1} \int_{0}^{1} K(t, s) \hat{p}(s) \hat{p}(t) d s d t .
$$

We can, however, first strengthen the conclusion of Lemma 2.4 in [19] to

$$
\int_{L_{c}(K)} p(x) q(x) q(t) d A \leqq \int_{L_{c}(K)} \hat{p}(x) \hat{q}(x) \hat{q}(t) d A,
$$

and then prove Lemma 2 in a way similar to the one used in the proof of the original version. Since the modifications are slight, the proof is thus omitted.

3. Positive operators. Let $B$ be a real Banach space. A closed subset $K$ of $B$ is a cone if the following conditions are satisfied:

(i) If $x \in K$ and $y \in K$, then $x+y \in K$. 
(ii) If $x \in K$ and $t \geqq 0$, then $t x \in K$.

(iii) If $x \in K$ and $x \neq 0$, then $-x \notin K$.

A cone is said to be solid if it contains interior elements. An operator $T$ defined on $B$ is said to be positive (with respec to $K$ ) if it leaves the cone $K$ invariant and $u_{0}$-positive if nonzero $u_{0}$ exists in $K$ so that for every nonzero $u$ in $K$, positive numbers $s, t$ and positive integer $p$ can be found satisfying $s u_{0} \leqq T^{p} u \leqq t u_{0}$ where we write $x \leqq y$ if $y-x \in K$ and we write $x \prec y$ if $y-x \in K$ and $y-x \neq 0$.

Lemma 3. ([13, 14, 15, 16]). Let $T$ be a linear, $u_{0}$-positive and completely continuous operator defined on a real Banach space $B$ with solid cone $K$. Then $T$ has exactly one (normalized) eigenvector in $K$ and the corresponding eigenvalue is simple, positive, and larger than the absolute value of any other eigenvalue.

Let $B^{\prime}$ denote the dual space of continuous linear functionals on $B$, and let $K^{\prime}$ denote the dual cone of all elements of $B^{\prime}$ that are nonnegative on $K$, i.e.,

$$
K^{\prime}=\left\{x^{\prime} \in B^{\prime}:\left\langle x, x^{\prime}\right\rangle \geqq 0 \text { for all } x \in K\right\},
$$

where $\left\langle x, x^{\prime}\right\rangle$ denotes the number $x^{\prime}(x)$. If $T$ is a linear operator defined on $B$, we shall denote its special radius by $r(T)$, i.e.,

$$
r(T)=\sup \{|\lambda|: \lambda \in \sigma(T)\} .
$$

LEMMA 4. ([17, Lemma 3.3]). Let $T$ be a linear, positive and completely continuous operator defined on a real Banach space $B$ with cone $K$. For $x \neq 0$, let

$$
S=\left\{\lambda \in R: \lambda\left\langle x, x^{\prime}\right\rangle \leqq\left\langle T x, x^{\prime}\right\rangle, x^{\prime} \in K^{\prime}\right\} .
$$

Let

$$
r_{x}(T)= \begin{cases}\sup S & \text { if } S \neq \varnothing \\ -\infty & \text { if } S=\varnothing\end{cases}
$$

Then $r_{x}(T) \leqq r(T)$.

The set of $2 n$-times continuously differentiable real functions $C^{(2 n)}[0,1]$ equipped with the norm

$$
\|f\|=\max _{1 \leqq j \leqq 2 n}\left\{\sup _{0 \leqq t \leqq 1}\left|f^{(j)}(t)\right|\right\}
$$

is a Banach space. In the sequel, we shall denote the subset

$$
\begin{array}{r}
\left\{f \in C^{(2 n)}[0,1]: f^{(2 k)}(0)=0=f^{(2 k)}(1) \text { for } k=0,1, \cdots, n-1,\right. \\
\left.\quad \text { and }(-1)^{k} f^{(2 k)}(t) \geqq 0 \text { for } 0 \leqq k \leqq n-1 \text { and } 0 \leqq t \leqq 1\right\}
\end{array}
$$


of $C^{(2 n)}[0,1]$ by $K_{n} . \quad K_{n}$ is a solid cone of $C^{(2 n)}[0,1]$ as may be verified directly.

4. The Green's functions associated with (1). Let the function $G_{1}(t, s)$ and its successive iterates be defined as follows

$$
\begin{gathered}
G_{1}(t, s)= \begin{cases}t(1-s) & \text { if } 0 \leqq t \leqq s \\
s(1-t) & \text { if } s \leqq t \leqq 1\end{cases} \\
G_{n}(t, s)=\int_{0}^{1} G_{1}(t, r) G_{n-1}(r, s) d r \quad(n=2,3, \cdots) .
\end{gathered}
$$

If $g(t)$ is any function continuous in the interval $[0,1]$, then it is easily verified that the unique solution of the differential system

$$
\begin{aligned}
(-1)^{n} x^{(2 n)}(t) & =g(t) \\
x^{(2 k)}(0) & =0=x^{(2 k)}(1), \quad k=0,1, \cdots, n-1
\end{aligned}
$$

is

$$
x(t)=\int_{0}^{1} G_{n}(t, s) g(s) d s .
$$

In fact $G_{n}(t, s)$ is the familiar Green's function of the system. Consequently, system (1) can be transformed into an integral equation of the form

$$
\lambda T_{n} x=x .
$$

Where $T_{n}: C^{(2 n)}[0,1] \rightarrow C^{(2 n)}[0,1]$ is defined by

$$
\left(T_{n} x\right)=\int_{0}^{1} G_{n}(t, s) p(s) x(s) d s .
$$

$T_{n}$ is clearly linear, furthermore, since $G_{n}(t, s)$ and $p(s)$ are continuous, $T_{n}$ is also compact.

Lemma 5. For each positive integer $m, G_{m}(t, s)$ is positive in the interior of $[0,1] \times[0,1]$ and zero on the boundary.

Lemma 6. $G_{n}(t, s)=G_{n}(s, t)=G_{n}(1-s, 1-t)=G_{n}(1-t, 1-s)$, $G_{n}(1-t, s)=G_{n}(1-s, t)$ and

$$
\int_{0}^{1} G_{1}(t, s) d s=t(1-t) / 2 .
$$

LEMMA 7. Let $y$ be a continuous, nonnegative function which does not vanish identically in $[0,1]$, then positive $\alpha$ can be found such that for $t \in[0,1]$ 


$$
\alpha t(1-t) \leqq \int_{0}^{1} G_{1}(t, s) y(s) d s
$$

Lemma 5 follows directly from the definition of $G_{m}(t, s)$. Lemma 7 is a result in [14, p. 283]. Lemma 6 is a result of Cheng [6, Corollary 4.6] which also follows from direct verification. Note that Lemma 6 implies that $G_{n}(t, s)$ takes on the same value at the corners of any parallelogram lying in the square $[0,1] \times[0,1]$ and having sides parallelled to the diagonals of $[0,1] \times[0,1]$.

Lemma 8. $G_{n}(t, s)$ is quasiconcave on $[0,1] \times[0,1]$.

Proof. We start by defining a sequence of polynomials $f_{1}, f_{2}, f_{3}, \ldots$ by means of the conditions

$$
\begin{array}{ll}
f_{1}(x)=x / 2 & \\
f_{n}^{\prime}(x)=f_{n-1}(x) & n>1 \\
f_{2 n-1}(-1)=0 & n>1 \\
f_{2 n}(x)=f_{2 n}(-x) & n \geqq 1 .
\end{array}
$$

Denote the points $(-1,-1),(0,0),(1,-1)$ and $(0,-2)$ by $A, B, C$ and $D$ respectively. Let $H_{n}(u, v)$ be the function

$$
H_{n}(u, v)= \begin{cases}(-1)^{n}\left[f_{2 n}(u)-f_{2 n}(v)\right] & \text { if }(u, v) \in \Delta A B C \\ (-1)^{n}\left[f_{2 n}(u)-f_{2 n}(-v-2)\right] & \text { if }(u, v) \in \triangle A D C .\end{cases}
$$

Under the change of variables

$$
\begin{aligned}
t & =(u-v) / 2, & & s=(u+v+2) / 2 \\
u & =t+s-1, & & v=s-t-1
\end{aligned}
$$

it is easily seen that the square with vertices $A, B, C$ and $D$ is transformed into $[0,1] \times[0,1]$. We assert that

$$
G_{n}(t, s)=H_{n}(t+s-1, s-t-1), \quad(t, s) \in[0,1] \times[0,1] .
$$

Indeed, if we set $G_{n}^{\prime}(t, s)=H_{n}(t+s-1, s-t-1)$, we may verify directly that $G_{n}^{\prime}(t, s)$, when regarded as a function of $t$ with $s$ fixed, satisfies the following conditions:

(i) Together with its first $2 n-2$ derivatives, it is continuous on $[0,1]$. At the point $t=s$, the $(2 n-1)$ th derivative has an upward jump $(-1)^{n}$.

(ii) Its $2 n$th derivative is identically zero.

(iii) It satisfies the boundary conditions in (1).

Since the Green's function is the only function with the above properties $G_{n}(t, s)=G_{n}^{\prime}(t, s)$. 
Since for each $m \leqq n, G_{m}(t, s)>0$ in the interior of $[0,1] \times$ $[0,1]$, it is clear that $H_{m}(u, v)>0$ for $-1 \leqq v<u \leqq 0$. Hence, $(-1)^{m}\left(f_{2 m}(u)-f_{2 m}(v)\right)>0$ for $-1 \leqq v<u \leqq 0$, that is, $(-1)^{m} f_{2 m}$ is strictly increasing in $[-1,0]$. Since $f_{2 m-1}(-1)=0,(-1)^{m} f_{2 m}^{\prime}=(-1)^{m} f_{2 m-1}>0$ and $(-1)^{m} f_{2 m-1}^{\prime \prime}=(-1)^{m} f_{2 m-3}=(-1)(-1)^{m-1} f_{2 m-3}<0$ over $(-1,0]$. We therefore conclude that $(-1)^{m} f_{2 m-1}$ is positive and concave over $(-1,0]$.

To show that for every $c>0, L\left(G_{n}, c\right)$ is a convex set, it is sufficient to show that $L\left(H_{n}, c\right)$ is bounded on one side of the line $v=-1$ by a concave curve, and on the other side by a convex curve. But in view of Lemma 6 (and the statements following Lemma 7), it suffices to show that the part of $L\left(H_{n}, c\right)$ contained in the triangle $-1 \leqq v<u \leqq 0$ is bounded by a concave curve. For this purpose, we implicitly differentiate $H_{n}(u, v)=c$ to obtain [8, p. 223]

$$
\frac{d v}{d u}=-\frac{(-1)^{n} f_{2 n}(u)}{(-1)^{n+1} f_{2 n}^{\prime}(v)}=\frac{f_{2 n-1}(u)}{f_{2 n-1}(v)} \neq 0
$$

and

$$
\begin{aligned}
\frac{d^{2} v}{d u^{2}} & =-\frac{\left[f_{2 n}^{\prime}(v)\right]^{2}(-1)^{n} f_{2 n}^{\prime \prime}(u)+\left[f_{2 n}^{\prime}(u)\right]^{2}(-1)^{n+1} f_{2 n}^{\prime \prime}(v)}{(-1)^{n+1}\left[f_{2 n}^{\prime}(v)\right]^{3}} \\
& =\frac{\left[f_{2 n}(u)\right]^{2}}{f_{2 n}^{\prime}(v)}\left\{\frac{f_{2 n}^{\prime \prime}(u)}{\left[f_{2 n}^{\prime}(u)\right]^{2}}-\frac{f_{2 n}^{\prime \prime}(v)}{\left[f_{2 n}^{\prime}(v)\right]^{2}}\right\} \\
& =\frac{\left[f_{2 n-1}(u)\right]^{2}}{f_{2 n-1}(v)}\left[\frac{1}{f_{2 n-1}(v)}-\frac{1}{f_{2 n-1}(u)}\right]^{\prime}
\end{aligned}
$$

for $-1<v<u \leqq 0$. But since $(-1)^{n} f_{2 n-1}$ is positive and concave over $(-1,0]$, thus $1 /(-1)^{n} f_{2 n-1}$ is convex over $(-1,0]$ (see $[2, \mathrm{p} .156]$ ), so that $\left(1 /(-1)^{n} f_{2 n-1}\right)^{\prime}$ is increasing in $(-1,0]$. Consequently,

$$
\frac{\left[f_{2 n-1}(u)\right]^{2}}{(-1)^{n} f_{2 n-1}(v)}\left[\frac{1}{(-1)^{n} f_{2 n-1}(v)}-\frac{1}{(-1)^{n} f_{2 n-1}(u)}\right]^{\prime} \leqq 0
$$

for $-1<v<u \leqq 0$. This shows that $d^{2} v / d u^{2} \leqq 0$ for $-1<u \leqq 0$ so that the part of $L\left(H_{n}, c\right)$ contained in the triangle $-1 \leqq v<u \leqq 0$ is indeed bounded above by a concave curve. The proof is complete.

5. Existence of eigenvalues. It is known (see for instance [7, pp. 228-230, and 9, 1]) that the selfadjoint and positive definite eigenvalue problem (1) has a smallest positive eigenvalue which is simple and the corresponding eigenfunctions have no zeros in $(0,1)$. Here, we shall give an alternate proof which also shows that the corresponding eigenfunctions belong to $K_{n}$. For this purpose, we first show that the operator $T_{n}$ defined in the last section is $u_{0}$ positive with respect to $K_{n}$. 
Let $x$ be an arbitrary nonzero element of $K_{n}$. Recall that for each positive integer $m, T_{m} x$ is the unique solution of

$$
\begin{aligned}
& (-1)^{m} y^{(2 m)}=p x \\
& y^{(2 k)}(0)=0=y^{(2 k)}(1), \quad k=0,1, \cdots, m-1 .
\end{aligned}
$$

In view of this and (7),

$$
\left(T_{m} x\right)^{\prime \prime}=-T_{m-1} x \quad \text { if } \quad m>1 ;
$$

furthermore, by Lemma $5, T_{m} x \in K_{m}$ for each $m \leqq n$. Let

$$
u_{0}=T_{n-1} u^{*},
$$

where $u^{*}(t)=t(1-t)$. Since $u^{*} \in K_{j}$ for any $j \geqq 1, u_{0} \in K_{m}$ for any $m \geqq 1$, and in particular, $u_{0} \in K_{n}$. We assert that positive numbers $\alpha$ and $\beta$ can be found such that

$$
\alpha u_{0} \leqq T_{n} x \leqq \beta u_{0} .
$$

First recall from Lemma 7 that positive number $\alpha$ can be found such that

$$
\alpha u^{*}(t) \leqq\left(T_{1} x\right)(t), \quad 0 \leqq t \leqq 1
$$

Thus

$$
\alpha u^{*}(t) \leqq\left(T_{1} x\right)(t) \leqq \beta u^{*}(t), \quad 0 \leqq t \leqq 1
$$

where $\beta=\max \{p(t) x(t): 0 \leqq t \leqq 1\}$. Consequently, by (9) and induction

$$
\begin{aligned}
(-1)^{n-1}\left(T_{n} x-\alpha u_{0}\right)^{(2 n-2)}(t) & =\left(T_{1} x-\alpha u^{*}\right)(t) \geqq 0 \\
& \vdots \\
(-1)\left(T_{n} x-\alpha u_{0}\right)^{\prime \prime}(t) & =\left(T_{n-1} x-\alpha T_{n-2} u^{*}\right)(t) \geqq 0
\end{aligned}
$$

for $0 \leqq t \leqq 1$. In other words, we have shown that $T_{n} x-\alpha u_{0} \in K_{n}$. Similarly, we can show that $\beta u_{0}-T_{n} x \in K_{n}$.

We conclude that $T_{n}$ is $u_{0}$-positive so that according to Lemma $3, T_{n}$ has exactly one (normalized) eigenvector in $K_{n}$ and the corresponding eigenvalue is simple, positive, and larger than the absolute value of any other eigenvalue. In view of (6), we have thus shown the following

THEOREM 1. The eigenvalue problem (1) has exactly one (normalized) eigenvector in $K_{n}$ and the corresponding eigenvalue is simple, positive, and smaller than the absolute value of any other eigenvalue. 
In the sequel, we shall denote the smallest eigenvalue of (1) by $\lambda(p)$.

CoRollary 1. Let $x(t)$ be an eigenfunction of (1) corresponding to $\lambda(p)$, then $x(t) \neq 0$ for any $t \in[0,1]$.

Proof. Since $\lambda(p)$ is simple, we may assume $x(t) \geqq 0$ for $0 \leqq t \leqq 1$. If $n=1$, then

$$
x^{\prime \prime}=-p x \leqq 0
$$

on $[0,1]$. If $n>1$, then by Theorem $1, x^{\prime \prime} \leqq 0$ on $[0,1]$ also. Thus $x$ is a nonnegative and concave function. Since $x(0)=0=x(1), x(t)$ cannot vanish in $(0,1)$.

CoRollary 2. If $p(t)$ in symmetric in $[0,1]$ (i.e., $p(t)=p(1-t)$ for $t \in[0,1])$, and if $x(t)$ is an eigenfunction corresponding to $\lambda(p)$, then $x(t)=x(1-t)$ for $t \in[0,1]$.

Proof. We may verify by direct substitution into (1) that $x(1-t)$ is also an eigenfunction corresponding to $\lambda(p)$. Consequently, $x(t)=\alpha x(1-t)$ for some nonzero number $\alpha$. But since $x(1 / 2) \neq 0$, thus $\alpha=1$ as required.

CoRollary 3. The spectral radius $r\left(T_{n}\right)$ is equal to $\lambda^{-1}(p)$.

6. Isoperimetric inequalities. In this section, we shall prove the following result as asserted in $\S 1$.

THEOREM 2. Let $p(t)$ be a positive and continuous function defined on $[0,1]$, and let $\breve{p}(t)$ and $\hat{p}(t)$ be respectively the rearrangements of $p(t)$ in symmetrically increasing and decreasing order. Consider the three eigenvalue problems (1) and

$$
\begin{array}{ll}
u^{(2 n)}+(1-)^{n} \grave{p}(t) u=0 & \\
u^{(2 k)}(0)=0=u^{(2 k)}(1), & k=0,1, \cdots, n-1 \\
v^{(2 n)}+(-1)^{n} \hat{p}(t) v=0 & \\
v^{(2 k)}(0)=0=v^{(2 k)}(1), & k=0,1, \cdots, n-1 .
\end{array}
$$

Denote their least positive eigenvalues by $\lambda(p), \lambda(\check{p})$ and $\lambda(\hat{p})$ respectively. Then

$$
\lambda(\hat{p}) \leqq \lambda(p) \leqq \lambda(\check{p}) .
$$

We first show that $\lambda(p) \leqq \lambda(\check{p})$. We recall that $[7$, p. 239 and 
1] the least positive eigenvalue of (1) is equal to

$$
\min \left\{\int_{0}^{1}\left[x^{(n)}\right]^{2} / \int_{0}^{1} p x^{2}\right\}
$$

where the minimum is taken over functions $x \in C^{(2 n)}[0,1]$ that satisfy the boundary conditions in (1) and for which the denominator is positive. Furthermore, no function other than the corresponding eigenfunction yields the minimum.

Let $u(t)$ be a nonnegative eigenfunction of (12) corresponding to $\lambda(\breve{p})$. Since $\check{p}(t)=\check{p}(1-t)$ for $t \in[0,1]$, by Corollaries 1 and 2 , $u(t)$ is symmetric in $[0,1]$, positive for $0<t<1$ and concave on $[0,1]$. Consequently, $u^{2}(t)$ is together with $u(t)$, symmetrically decreasing so that $\breve{p}(t)$ and $u^{2}(t)$ are oppositely ordered. But then by Lemma 1 ,

$$
\begin{aligned}
\lambda(\check{p}) & =\int_{0}^{1}\left[u^{(n)}\right]^{2} / \int_{0}^{1} \check{p} u^{2} \geqq \int_{0}^{1}\left[u^{(n)}\right]^{2} / \int_{0}^{1} p u^{2} \\
& \geqq \min \left\{\int_{0}^{1}\left[x^{(n)}\right]^{2} / \int_{0}^{1} p x^{2}\right\}=\lambda(p)
\end{aligned}
$$

as required.

Next we show that $\lambda(\hat{p}) \leqq \lambda(p)$. For this purpose, we need the following

THEOREM 3. The least positive eigenvalue of (1) satisfies

$$
\lambda^{-1}(p)=\max \frac{\int_{0}^{1} \int_{0}^{1} G_{n}(t, s) p(s) u(s) u(t) d s d t}{\int_{0}^{1} u^{2}(s) d s}
$$

where the maximum is taken over nonzero elements in $K_{n}$. Furthermore, the unique function, except for a constant multiple, which yields the maximum is the eigenfunction corresponding to $\lambda(p)$.

Proof. According to Lemma 4 and Corollary 3, for any nonzero $x$ in $C^{(2 n)}[0,1]$,

$$
r_{x}\left(T_{n}\right) \leqq r(T)=\lambda^{-1}(p),
$$

so that

$$
\sup _{\substack{x \in K_{n} \\ x \neq 0}} r_{x}\left(T_{n}\right) \leqq \lambda^{-1}(p)
$$

Now for each nonzero $u$ in $K_{n}$, define the positive linear functional $u^{\prime} \in K_{n}^{\prime}$ by 


$$
\left\langle x, u^{\prime}\right\rangle=\int_{0}^{1} x(s) u(s) d s
$$

for all $x \in K_{n}$. Then for each $x \in K_{n}$, we have that

$$
\sup \left\{\lambda \in R: \lambda\left\langle x, u^{\prime}\right\rangle \leqq\left\langle T_{n} x, u^{\prime}\right\rangle\right\} \leqq r_{x}\left(T_{n}\right)
$$

and consequently, that

$$
\sup \left\{\lambda \in R: \lambda\left\langle u, u^{\prime}\right\rangle \leqq\left\langle T_{n} u, u^{\prime}\right\rangle\right\} \leqq r_{u}\left(T_{n}\right) \leqq \lambda^{-1}(p),
$$

and

$$
\sup _{\substack{u \in K \\ u \neq 0}} \frac{\int_{0}^{1}\left(T_{n} u\right)(s) u(s) d s}{\int_{0}^{1} u^{2}(s) d s} \leqq r_{u}\left(T_{n}\right) \leqq \lambda^{-1}(p)
$$

Since we have equality when $u$ is equal to a constant multiple of the eigenfunction corresponding to $\lambda(p)$, the first part of the theorem is proven.

To prove the remainder of the theorem, let $v \in K_{n}$ be such that $\lambda^{-1}(p)=\left\langle T_{n} v, v\right\rangle /\langle v, v\rangle$. Then

$$
\frac{\left\langle T_{n} v, v\right\rangle}{\langle v, v\rangle} \leqq r_{v}\left(T_{n}\right) \leqq \lambda^{-1}(p)=\frac{\left\langle T_{n} v, v\right\rangle}{\langle v, v\rangle}
$$

shows that $r_{v}\left(T_{n}\right)=\left\langle T_{n} v, v\right\rangle /\langle v, v\rangle$. It follows that $\left\langle T_{n} v-\right.$ $\left.r_{v}\left(T_{n}\right) v, x^{\prime}\right\rangle \geqq 0$ for all $x^{\prime} \in K_{n}^{\prime}$, and consequently, by the Krein-Rutman theorem [15, Theorem 1.1], that $T_{n} v-r_{v}\left(T_{n}\right) v \in K_{n}$. We assert that $v$ is an eigenfunction corresponding to $\lambda(p)$. If not, there would exist a positive number $\alpha$ and a positive integer $m$ such that

$$
T_{n}^{m}\left(T_{n} v-r_{v}\left(T_{n}\right) v\right)=T_{n}\left(T_{n}^{m} v\right)-r_{v}\left(T_{n}\right)\left(T_{n}^{m} v\right) \succ \alpha u_{0}
$$

where $u_{0}$ is given by (10). Let $z=T_{n}^{m} v$. Since $z \in K_{n}$, there exists a positive number $\beta$ (as can be seen from (11)) such that $z>\beta u_{0}$. Hence, for sufficiently small $\varepsilon>0$,

$$
T_{n} z-r_{v}\left(T_{n}\right) z-\varepsilon z>(\alpha-\varepsilon \beta) u_{0}
$$

where $(\alpha-\varepsilon \beta)>0$. Consequently,

$$
\frac{\left\langle T_{n} z, x^{\prime}\right\rangle}{\left\langle z, x^{\prime}\right\rangle} \geqq r_{z}\left(T_{n}\right) \geqq r_{z}\left(T_{n}\right)+\varepsilon,
$$

which contradicts the fact that $r_{z}\left(T_{n}\right) \leqq \lambda^{-1}(p)=r_{v}\left(T_{n}\right)$. The proof is complete.

We remark that the proof given above is similar to that of Theorem 3.1 in [12]. However we feel that there are enough differences to include it here. 
Now let $u$ be the normalized eigenfunction corresponding to $\lambda(p)$. Then

$$
\lambda^{-1}(p)=\frac{\int_{0}^{1} \int_{0}^{1} G_{n}(t, s) p(s) u(s) u(t) d s d t}{\int_{0}^{1} u^{2}(s) d s} .
$$

Let $\hat{u}$ be the rearrangement of $u$ in symmetrically decreasing order, then by Lemmas 2 and 8 ,

$$
\int_{0}^{1} \int_{0}^{1} G_{n}(t, s) p(s) u(s) u(t) d s d t \leqq \int_{0}^{1} \int_{0}^{1} G_{n}(t, s) \hat{p}(s) \hat{u}(s) \hat{u}(t) d s d t .
$$

Thus

$$
\begin{aligned}
\lambda^{-1}(p) & \leqq \frac{\int_{0}^{1} \int_{0}^{1} G_{n}(t, s) \hat{p}(s) \hat{u}(s) \hat{u}(t) d s d t}{\int_{0}^{1} \hat{u}^{2}(s) d s} \\
& \leqq \max _{\substack{v \in K_{n} \\
v \neq 0^{n}}} \frac{\int_{0}^{1} \int_{0}^{1} G_{n}(t, s) \hat{p}(s) v(s) v(t) d s d t}{\int_{0}^{1} v^{2}(s) d s} \\
& =\lambda^{-1}(\hat{p}) .
\end{aligned}
$$

Consequently, $\lambda(\hat{p}) \leqq \lambda(p)$ as required. The proof of Theorem 2 is complete.

7. Conclusion remarks. We remark that in Theorem $2, \lambda(\hat{p})=$ $\lambda(p)$ only if $p \equiv \hat{p}$. Indeed, if $\lambda(\hat{p})=\lambda(p)$, then by Theorem 3 , an eigenfunction $u$ corresponding to $\lambda(\hat{p})$ is also an eigenfunction corresponding to $\lambda(p)$. Substitute $u$ into (1) and (12) respectively, we see that

$$
u^{(2 n)}+(-1)^{n} p(t) u=u^{(2 n)}+(-1)^{n} \hat{p}(t) u
$$

for $0<t<1$. Consequently, $p(t)=\hat{p}(t)$ for $0<t<1$ and by continuity $p(t)=\hat{p}(t)$ for $0 \leqq t \leqq 1$. Similarly, we can also show that $\lambda(\check{p})=\lambda(p)$ only if $p \equiv \check{p}$.

We have mentioned that Beesack and Schwarz [5] and Banks [3] proved $\lambda(\hat{p}) \leqq \lambda(p)$ for $n=1$ and 2 respectively. However, a close examination of their proofs reveals the fact that in order to establish by similar arguments the more general result, we shall run into the difficulty in constructing from a nonnegative function $u$ (satisfying the boundary conditions in (1)) two functions $\hat{u}$ and $v$, where $\hat{u}$ is the rearrangement of $u$ in symmetrically decreasing order and $v$ is symmetric in $[0,1]$ such that 


$$
\int_{0}^{1} u^{(n)}=\int_{0}^{1} v^{(n)}
$$

and $\widehat{u}(t) \leqq v(t)$ for $0 \leqq t \leqq 1$. This difficulty we have avoided by employing an extremal characterization (which is essentially a minimax principle) of $\lambda^{-1}(p)$ and a rearrangement inequality. In view of the fact that a large body of minimax principles exists for positive operators [12, 17], our approach indicates that other isoperimetric eigenvalue problems (e.g., fixed end-points problems [3]) can similarly be solved, provided, of course, that Vollman's inequality can be applied. Moreover, since the rearrangement inequality of Vollman clearly depends on the quasiconcavity of the kernel $K(t, s)$, our approach also indicates a close connection between the quasiconcavity of Green's function and the optimality of eigenvalues depending on equimeasurable densities.

\section{REFERENCES}

1. W. Allegretto and C. A. Swanson, Camparison theorem for eigenvalues, Ann. Mat. Pura Appl., Ser. 4, 49 (1974), 81-107.

2. M. Avriel, Nonlinear Programming Analysis and Methods, Prentice Hall, Englewood Cliffs, New Jersey, 1976.

3. A. D. Banks, Bounds for the eigenvalues of nonhomogeneous hinged vibrating rods, J. Math. Mech., 16 (1967), 946-966.

4. P. R. Beesack, Isoperimetric inequalities for the nonhomogeneous champed rod and plate, J. Math. Mech., 8 (1959), 471-482.

5. P. R. Beesack and B. Schwarz, On the zeros of solutions of second order linear differential equations, Canad. J. Math., 8 (1956), 504-515.

6. S. S. Cheng, Ordinary differential operators and their convolution adjoints, Bulletin of the Institute of Math. Academia Sinica, 7 (1979), 443-459.

7. L. Collatz, The Numerical Treatment of Differential Equations, Springer-Verlag, Berlin, 1960.

8. R. Courant and F. John, Introduction to Calculus and Analysis, Vol. 2, WileyInterscience, New York, 1974.

9. U. Elias, Eigenvalue problems for the equation $L_{y}+\lambda p(x) y=0$, J. Differential Equation, 29 (1978), 28-57.

10. A. M. Fink, Comparison theorem for eigenvalues, Quart. Appl. Math., 28 (1970), 289-292.

11. G. H. Hardy, J. E. Littlewood and G. Pólya, Inequalities, 2nd ed., University Press, Cambridge, 1952.

12. M. S. Keener and C. C. Travis, Positive cones and focal points for a class of $n$th order differential equations, Trans. Amer. Math. Soc., 237 (1978), 331-351.

13. M. A. Krasnoselski, Topological Methods in the Theory of Nonlinear Integral Equations, Pergamon, New York, 1964.

14. - Positive Solutions of Operator Equations, Noordhoff, Geroningen, 1964.

15. M. G. Krein and M. A. Rutman, Linear operators leaving invariant a cone in a Banach space, Uspehi Mat. Nauk., 3 (1948), No. 1 (23), 3-95; Amer. Math. Soc. Transl. No. 26 (1950).

16. I. Marek, $u_{0}$-Positive operators and some of their applications, SIAM J. Appl. Math., 15 (1967), 484-494.

17. - Frobenius theory of positive operators: comparison theorems and ap- 
plications, SIAM J. Appl. Math., 19 (1970), 607-628.

18. G. Pólya and G. Szegö, Isoperimetric Inequalities in Mathematical Physics, Princeton, 1951.

19. T. E. Vollman, Inequalities for integral bilinear forms with applications to mechanical systems, Indiana Uni. Math. J., 26 (1977), 847-867.

Received May 7, 1980 and in revised form October 13, 1980. This work is partially supported by the National Science Council of the Republic of China.

National Tsing Hua University

HSINCHU, TAIWAN, 300

REPUBLIC OF CHINA 



\title{
PACIFIC JOURNAL OF MATHEMATICS
}

\section{EDITORS}

\author{
DONALD BABBITT (Managing Editor) \\ University of California \\ Los Angeles, CA 90024 \\ Hugo RossI \\ University of Utah \\ Salt Lake City, UT 84112 \\ C. C. MOORE and Arthur Agus \\ University of California \\ Berkeley, CA 94720
}

\section{J. DugundjI}

Department of Mathematics

University of Southern California

Los Angeles, CA 90007

R. FinN and J. Milgram

Stanford University

Stanford, CA 94305

\section{ASSOCIATE EDITORS}
R. ARENS
E. F. BeCKENBACH
B. H. NeumanN
F. WOLF
K. YoshidA

\section{SUPPORTING INSTITUTIONS}

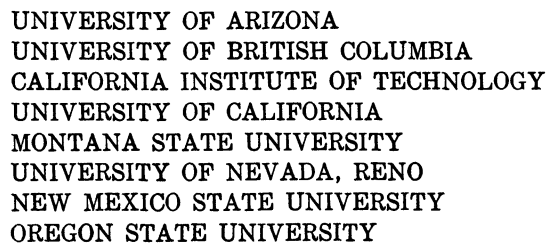

UNIVERSITY OF ARIZONA

UNIVERSITY OF BRITISH COLUMBIA

CALIFORNIA INSTITUTE OF TECHNOLOGY

UNIVERSITY OF CALIFORNIA

MONTANA STATE UNIVERSITY

UNIVERSITY OF NEVADA, RENO

NEW MEXICO STATE UNIVERSITY

OREGON STATE UNIVERSITY

\author{
UNIVERSITY OF OREGON \\ UNIVERSITY OF SOUTHERN CALIFORNIA \\ STANFORD UNIVERSITY \\ UNIVERSITY OF HAWAII \\ UNIVERSITY OF TOKYO \\ UNIVERSITY OF UTAH \\ WASHINGTON STATE UNIVERSITY \\ UNIVERSITY OF WASHINGTON
}

The Supporting Institutions listed above contribute to the cost of publication of this Journal, but they are not owners or publishers and have no responsibility for its content or policies.

Mathematical papers intended for publication in the Pacific Journal of Mathematics should be in typed form or offset-reproduced, (not dittoed), double spaced with large margins. Please do not use built up fractions in the text of the manuscript. However, you may use them in the displayed equations. Underline Greek letters in red, German in green, and script in blue. The first paragraph or two must be capable of being used separately as a synopsis of the entire paper. Please propose a heading for the odd numbered pages of less than 35 characters. Manuscripts, in triplicate, may be sent to any one of the editors. Please classify according to the scheme of Math. Reviews, Index to Vol. 39. Supply name and address of author to whom proofs should be sent. All other communications should be addressed to the managing editor, or Elaine Barth, University of California, Los Angeles, California, 90024.

50 reprints to each author are provided free for each article, only if page charges have been substantially paid. Additional copies may be obtained at cost in multiples of 50 .

The Pacific Journal of Mathematics is issued monthly as of January 1966. Regular subscription rate: $\$ 102.00$ a year (6 Vols., 12 issues). Special rate: $\$ 51.00$ a year to individual members of supporting institutions.

Subscriptions, orders for numbers issued in the last three calendar years, and changes of address shoud be sent to Pacific Journal of Mathematics, P.O. Box 969, Carmel Valley, CA 93924, U.S.A. Old back numbers obtainable from Kraus Periodicals Co., Route 100, Millwood, NY 10546.

\section{PUBLISHED BY PACIFIC JOURNAL OF MATHEMATICS, A NON-PROFIT CORPORATION}

Printed at Kokusai Bunken Insatsusha (International Academic Printing Co., Ltd.). 8-8, 3-chome, Takadanobaba, Shinjuku-ku, Tokyo 160, Japan. 


\section{Pacific Journal of Mathematics}

Vol. 99, No. $2 \quad$ June, 1982

Thomas E. Armstrong and Karel Libor Prikry, On the semimetric on a

Boolean algebra induced by a finitely additive probability measure . . . .249

Walter Russell Bloom, Strict local inclusion results between spaces of

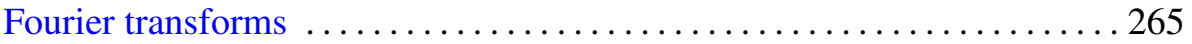

Richard Clark Brown, Notes on generalized boundary value problems in

Banach spaces. II. Infinite-dimensional extension theory ........... 271

Sui Sun Cheng, Isoperimetric eigenvalue problem of even order differential

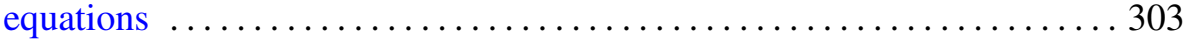

Lung O. Chung and Jiang Luh, Derivations of higher order and

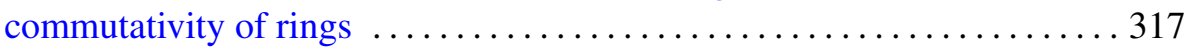

Ali Ahmad Fora, A fixed point theorem for product spaces . . . . . . . . . 327

Barry J. Gardner, Radical classes of regular rings with Artinian primitive

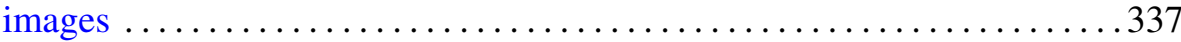

John Brady Garnett and Peter Wilcox Jones, BMO from dyadic BMO . . . 351

Allen E. Hatcher, On the boundary curves of incompressible surfaces . . . . 373

Richard Howard Hudson and Kenneth S. Williams, Resolution of

ambiguities in the evaluation of cubic and quartic Jacobsthal sums .....379

Viktor Losert, Counter-examples to some conjectures about doubly

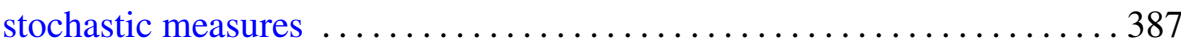

Kenneth Derwood Magill, Jr., P. R. Misra and Udai Bhan Tewari,

Structure spaces for sandwich semigroups

Mark Mandelker, Continuity of monotone functions

Kenneth Guy Miller, An index theorem and hypoellipticity on nilpotent Lie groups ......................................... 419

Evelyn M. Nelson, Homomorphisms of mono-unary algebras . . . . . . . . . 427

Marvin E. Ortel, The support of an extremal dilatation . . .

R. S. Pathak and O. P. Singh, Finite Hankel transforms of distributions . . . 439

Richard Cole Penney, The theory of ad-associative Lie algebras

Linda Ruth Sons, Zero distribution of functions with slow or moderate

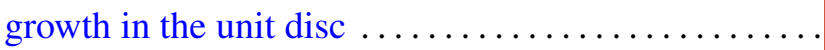

Russell Bruce Walker, Transversals to laminations 